\title{
A CRISE ESTRUTURAL DO CAPITAL NO BRASIL E SUAS INFLEXÕES NO ESTÁGIO SUPERVISIONADO EM SERVIÇO SOCIAL: ALGUMAS REFLEXÕES
}

\author{
Liane Soraya Viana da Silva ${ }^{1}$ \\ Mônica Barros da Nóbrega²
}

\begin{abstract}
Resumo: o presente texto pretende realizar uma análise sobre as principais inflexões da crise estrutural do capital iniciada a partir de 1970 sobre o Estágio Supervisionado em Serviço Social e as consequências do intenso processo de Reestruturação Produtiva, cujas bases são Flexibilização, Privatização e Desregulamentação, para a Formação e o Exercício Profissional. Nesse sentido, orientados pelo método crítico dialético, foi feita uma revisão da literatura sobre a temática, nos apropriando das discussões realizadas por Netto, Mezáros, Lewgoy, Ortiz, entre outros e analisamos os seguintes documentos: Diretrizes Curriculares da ABEPSS de 1996 e Política Nacional da Estágio (PNE).

Palavras-chave: Crise estrutural do capital; Estágio supervisionado; Serviço social.
\end{abstract}

\footnotetext{
${ }^{1}$ Mestranda em Serviço Social pelo Programa de pós-graduação em Serviço Social da Universidade Estadual da Paraíba - UEPB, Brasil. E-mail: lili.soraya@hotmail.com.

2 Docente do Departamento de Serviço Social/Universidade Estadual da Paraíba, Brasil. E-mail: monicabnobrega@yahoo.com.br.
} 